\title{
LOAD BEHAVIOR OF AN VERTICAL AXLE WIND TURBINE MODEL WITH A FOUR BLADES PERIODICALLY COUPLED AERODYNAMICALLY
}

\author{
Nelu CAZACU \\ "Dunarea de Jos" University of Galati, Faculty of Engineering \\ e-mail: nelu.cazacu@ugal.ro
}

\begin{abstract}
The paper is based on experiments conducted on the wind tunnel at low wind speeds $(<4.5 \mathrm{~m} / \mathrm{s})$, on an experimental wind turbine model of the Savonius type with four blades and a D/H ratio of 2.6. The four blades are periodically coupled aerodynamically. The model acted a DC generator with a speed multiplier. Experiments were performed by modifying the generator electrical charge. The results confirm the validity of the concept proposed.
\end{abstract}

KEYWORDS: Savonius rotor, low wind, wind tunnel

\section{Introduction}

In the classic structure of VAWT, the Savonius or " $\mathrm{S}$ " rotor model is considered representative for this class of turbines. The main advantages of the Savonius turbines are: very simple principle of operation, constructive simplicity and independence from the wind direction [1]. The main drawbacks are their low yield (maximum 14.81\%) and constructive difficulties at high wind speeds [1, 2].

A horizontal section through the turbine highlights the "S" shape (Fig. 1). For the position of the blade plane perpendicular to the wind, the highest of torque to the different resistance to the wind (Fig. 2) is obtained [1]. Differences between $D_{c v}$ and $D_{c x}$ resistors determine a result that produces a mechanical torque that determines the rotation. At wind speed $v$ the $\omega$ angular velocity and the blade tip $u$ are reached (Fig. 1). Other intermediate positions of the pair of blades gives different torque force values as measured by (2). There is also a dead point where the torque is zero and from which the turbine comes out due to inertia [3]. An increase in the VAWT efficiency of the Savonius type is achieved by changing the blade profile to create a slight deadweight load and then balancing faster pressures between the convex and concave areas. As a result, specific blade profiles have been developed, but the blade overlay and gap spacing have been developed (Fig. 4, Fig. 5) [4].

The power of wind depends on wind speed $(\mathrm{v})$, air density $(\rho)$ and swept area (A):

$$
P=0,5 \rho A v^{3}
$$

The power extracted from a wind power by a VAWT Savonius type depends by Drag force (5) is:

$$
D=0,5 C_{D} \rho(v-u)^{2} A
$$

where $\mathrm{u}$ is speed of blade and $\mathrm{P}$ is:

$$
P=D u=0,5 C_{D} \rho v^{3}\left(1-\frac{u}{v}\right)^{2} \frac{u}{w} A
$$

when:

$$
\lambda=T S D=u / v
$$

The extracted power (3) is:

$$
P=0,5 C_{D} \rho v^{3}(1-\lambda)^{2} \lambda A
$$

And the conversion efficiency is:

$$
\begin{gathered}
\eta=\frac{P}{P_{w}}=\frac{0,5 \rho(v-u)^{2} C_{D} u A}{0,5 \rho A v^{3}} \\
\eta=\frac{(v-u)^{2} C_{D} u}{v^{3}}
\end{gathered}
$$




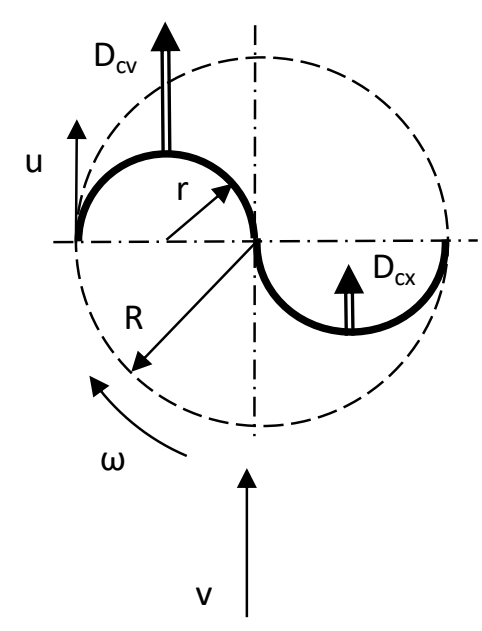

Fig. 1. Horizontal sections trough Savonius ("S"'- rotor) turbine [1]

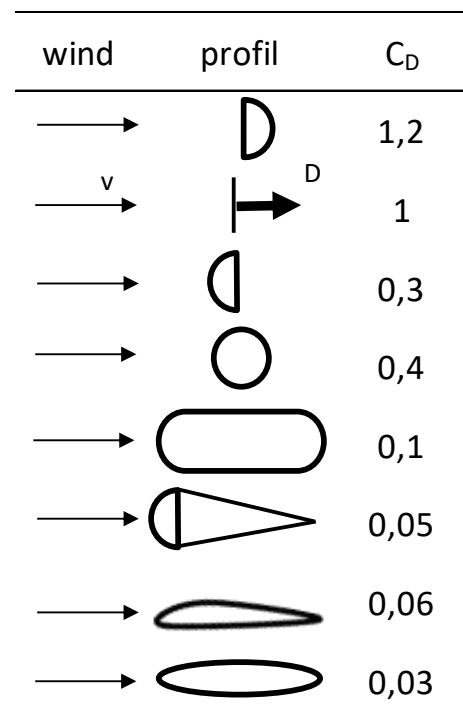

Fig. 2. Draft force for different shape [4]

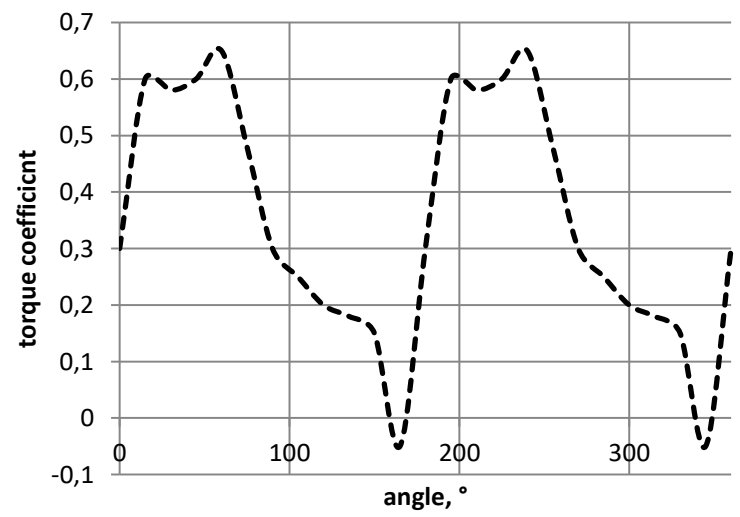

Fig. 3. Torque coefficient variation on the axis of an "S" turbine with the rotation angle [5]

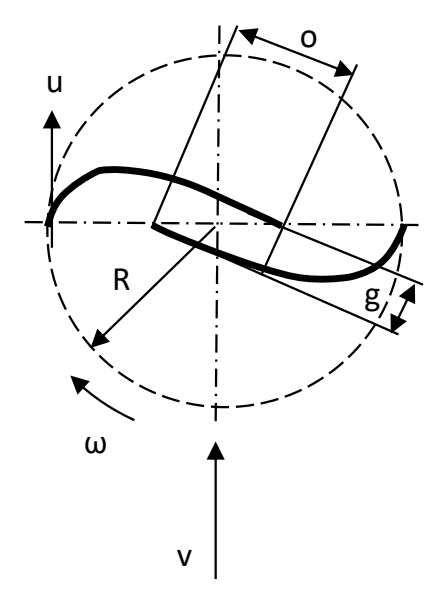

Fig. 4. The pair of blades Benesh with gap ( $g$ ) and overlay (a) [6]

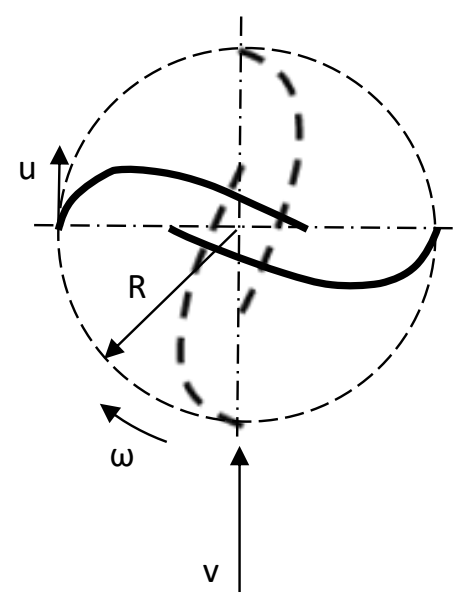

Fig. 5. Savonius with 2 level and one pair of blades (1PB) per level in Benesh profile

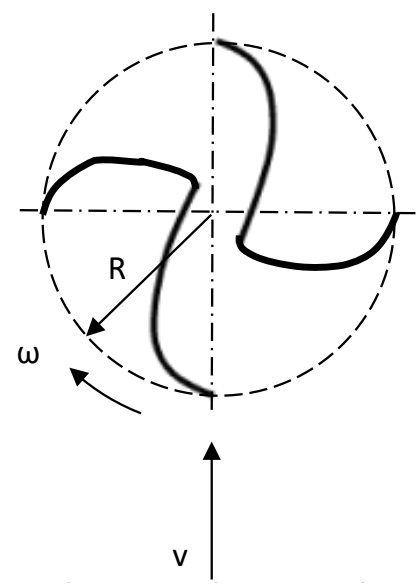

Fig. 6. Section of the real profile of the two pair of blades (2PB) turbine 


\section{notations:}

$v$ - wind velocity (input), $\mathrm{m} / \mathrm{s}$

$u$ - tip blade speed, $\mathrm{m} / \mathrm{s}$

$R$ - the radius of the disc base, $m$

$o$ - overlap, $m$

$d$ - width of blade, $m$

$h$ - height of blade, $m$

$\omega$ - angular speed, radians/s

$\lambda$ - specific speed

$C_{p}$ - power index

$D_{c v}$ - drag force for concave surface

$D_{c x}$ - drag force for convex surface

\section{abbreviation}

$V A W T$ - vertical axes wind turbine

$T S R$ - tip speed ratio

$P B$ - pair of blades

dc - direct current

Re - Reynolds number

EM - experimental model

VCC - positive potential

GND - ground potential

\section{Experimental conditions and regimes}

Experimental (EM) wind turbine models with a Savonius (S-rotor) vertical spindle with one and two pairs of blades (PB) and one level were developed and used as follows:

- Experimental model (EM) of VAWT type

Savonius with a level and a pair of blades (1L1PB).

- Experimental model (EM) of VAWT with a level and 2 pairs of aerodynamically coupled blades (1L2PB-ac).

Experiments were conducted on an open wind tunnel with a measuring area of $0.25 \mathrm{~m}^{2}(0.5 \mathrm{~m} \times 0.5$ $\mathrm{m})$ and a length of $1.25 \mathrm{~m}$, and an equalization zone of $2.5 \mathrm{~m}$ long. Measurements were made with: LCA6000 for wind speed and an electronic rev counter for the speed of rotation of the model.

The experiments were resumed from the proposed maximum speed $(4.5 \mathrm{~m} / \mathrm{s})$ to the lower wind speed limit. The mechanical and electrical load of the model has changed.

The test conditions are coded as follows:

- N - no load (mechanical or electrical);

- M - mechanical load (multiplier x 3.5 and rotor of dc generator);

- ML - idem M plus a white LED;

- ML1 - idem ML plus a $1 \mathrm{k} \Omega$ resistor (connected VCC to GND);

- ML1.5 - idem ML plus a $1.5 \mathrm{k} \Omega$ resistor (connected VCC to GND);

- ML2 - idem ML plus a $2 \mathrm{k} \Omega$ resistor (connected VCC to GND).

\section{Results and discussions}

The variation of the speed of the experimental models is shown in Fig. 7. Experimental models that have been tested at wind speeds of $0-4.5 \mathrm{~m} / \mathrm{s}$ without load immediately start rotation including low wind speeds (S1L1PB, N). EM with different loads (M, ML, ML1, ML1,5 and ML2) start wind speed rotation of more than $2 \mathrm{~m} / \mathrm{s}$ and the speed does not exceed 300 rpm.

TSR has a clear variation for EMs that are free (no load) and load tested (Fig. 8). Experimental models $\mathrm{N}$ and S1L1PB are sensitive to low wind speeds and reach $\lambda=0.8-1$. EM with load (M, ML, ML1, ML1,5 and ML2) have a maximum for $\lambda=0.4$ 0.5 at the maximum test speed of $4.5 \mathrm{~m} / \mathrm{s}$ and rotate for wind speed greater than $2 \mathrm{~m} / \mathrm{s}$.

The Re number variation is shown in Fig. 9 and Fig. 10. For TSR around 0.5 mA EM load (M, ML, ML1, ML1,5 and ML2) Re number has values before 40000-50000, being higher than in non-load tested models. The function of wind speed Re number has the same variation altitude as rotation (Fig. 7, Fig. 9).

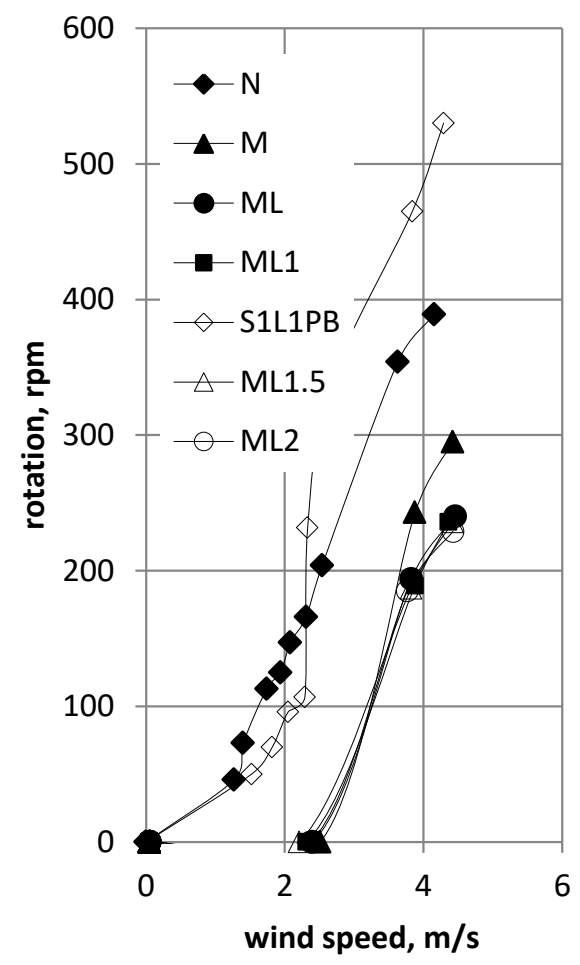

Fig. 7. Rotation speed variation with wind speed and for different loads 


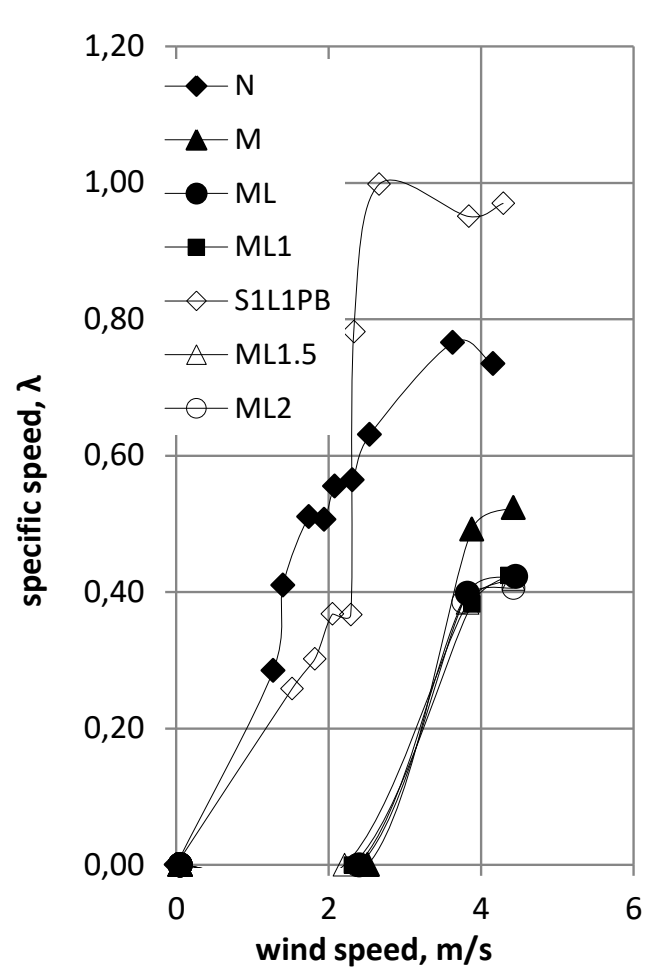

Fig. 8. TSR ( $\lambda$ ) with wind speed of EM for different load

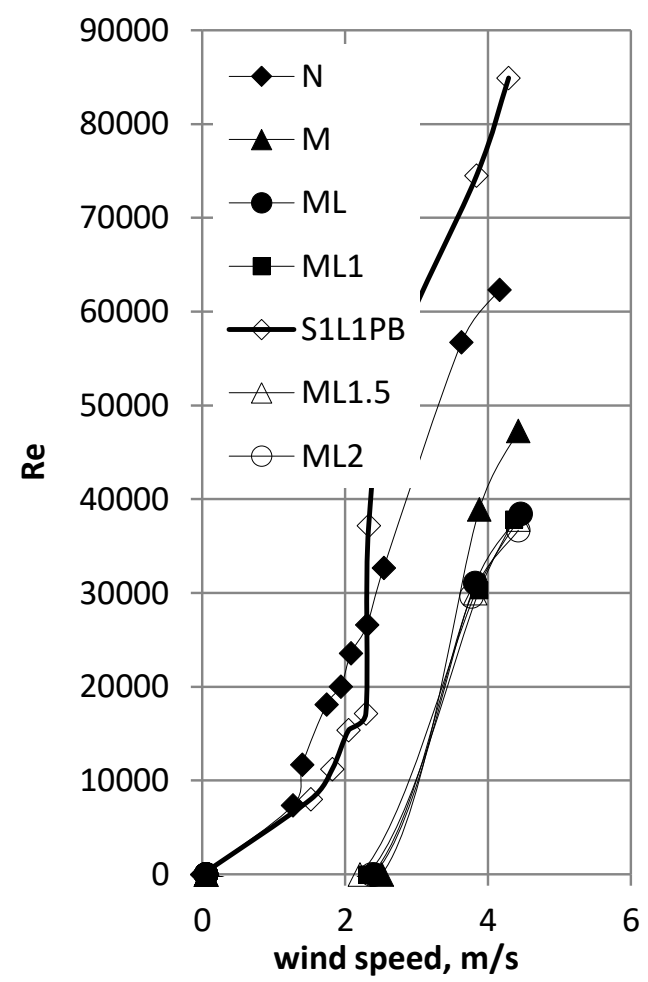

Fig. 9. Re number variation with wind speed for different loads of EM

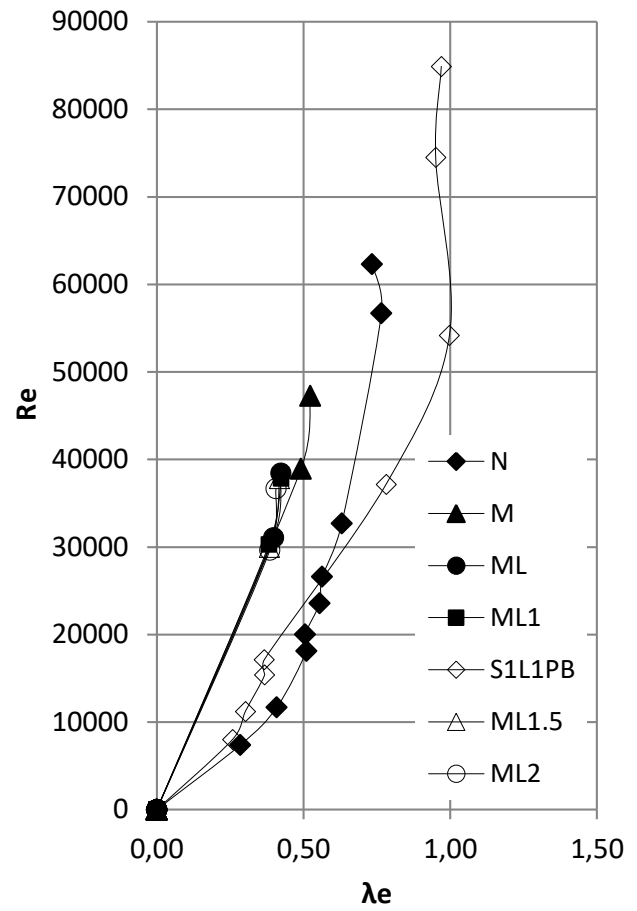

Fig. 10. Re number variations with TSR for experiments

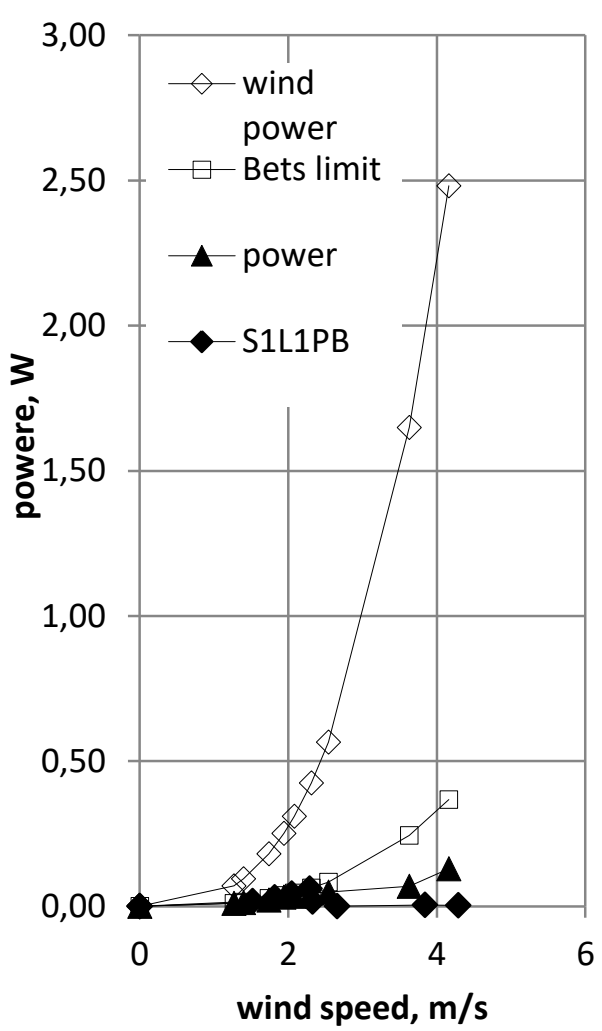

Fig. 11. Wind power, Betz limit (VAWT) and some power extracted by EM 


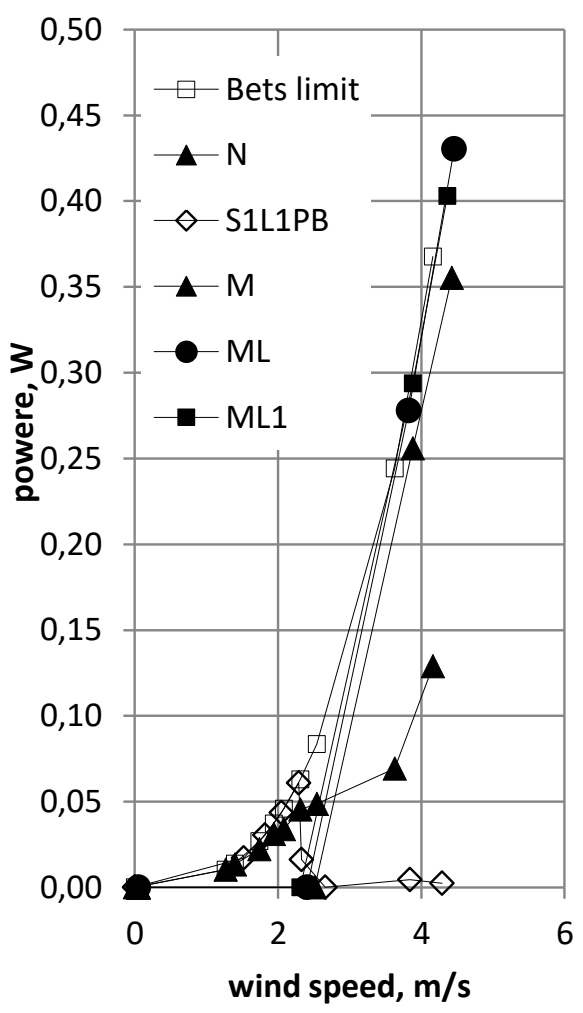

Fig. 12. Power for EM under experiments

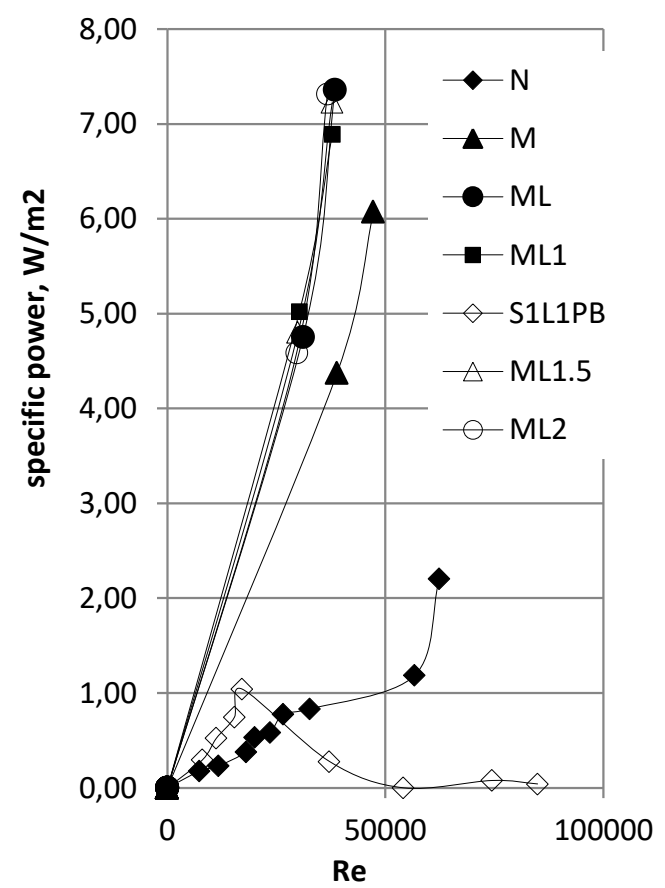

Fig. 13. Specific power for al experiments

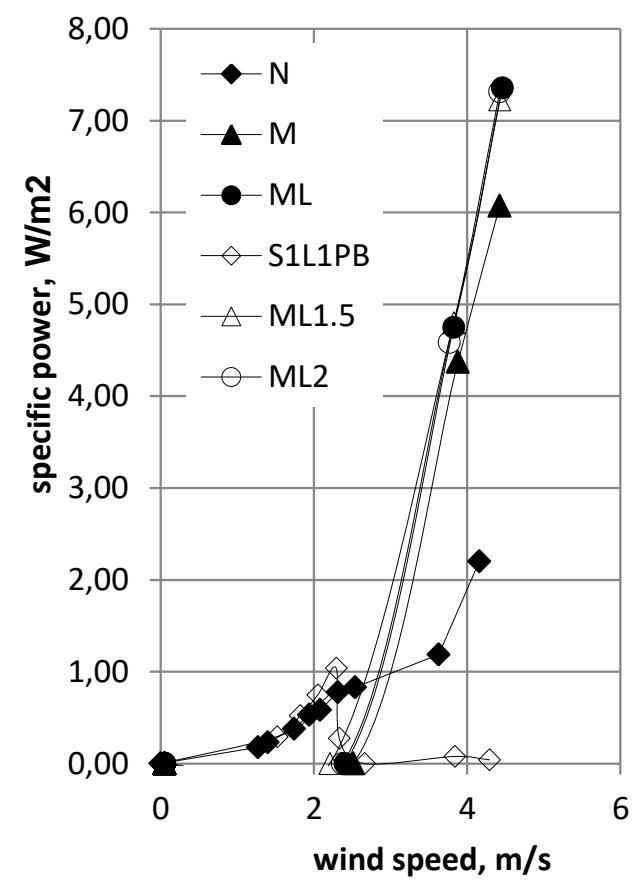

Fig. 14. Specific power with wind speed for all experiments

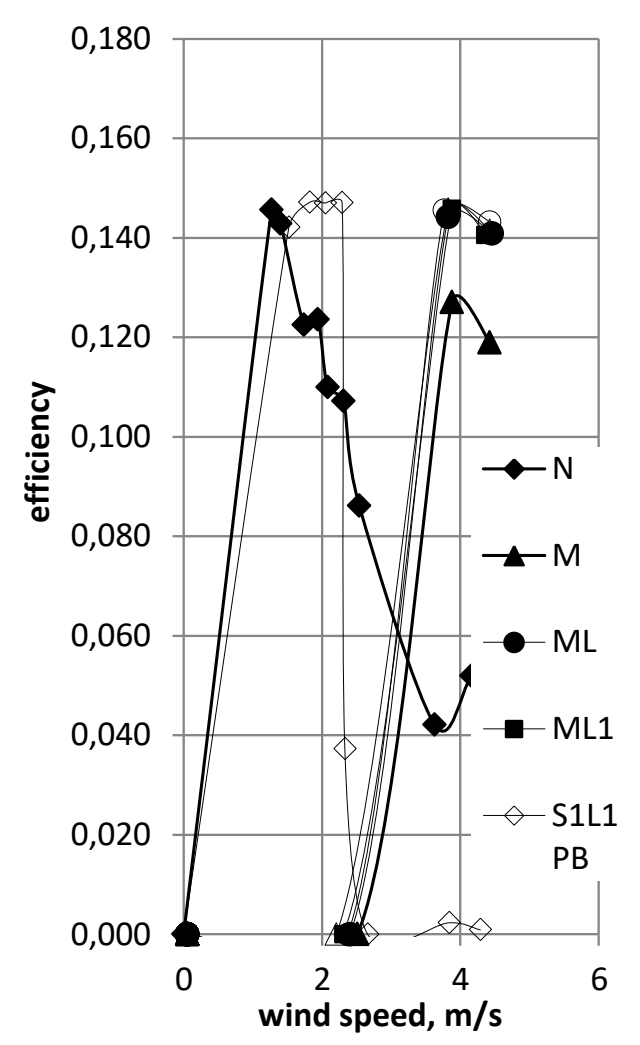

Fig. 15. Conversion efficiency with wind speed for all experiments 


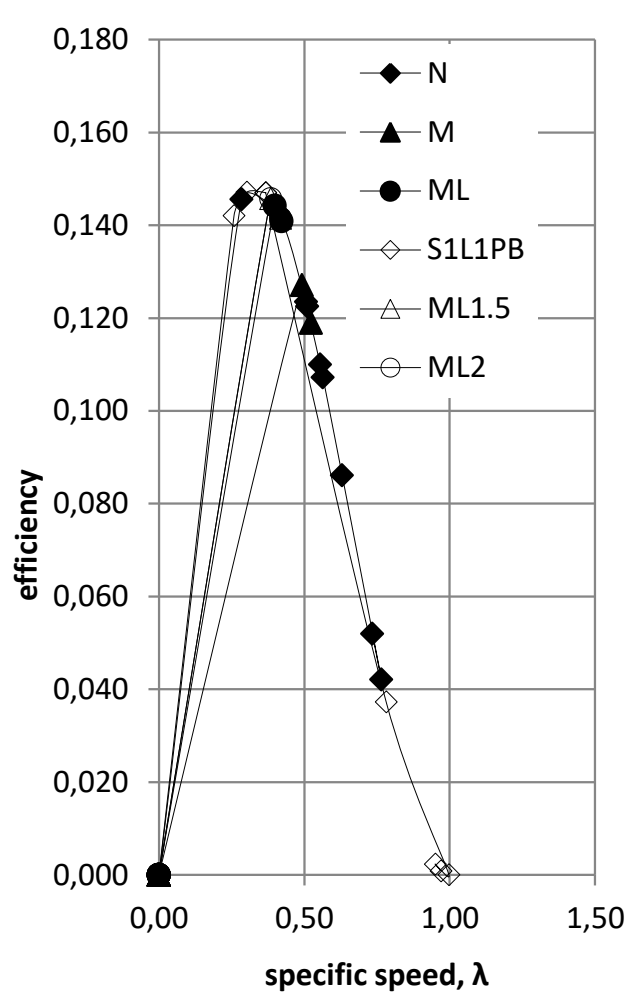

Fig. 16. Efficiency with TSR for all experiments

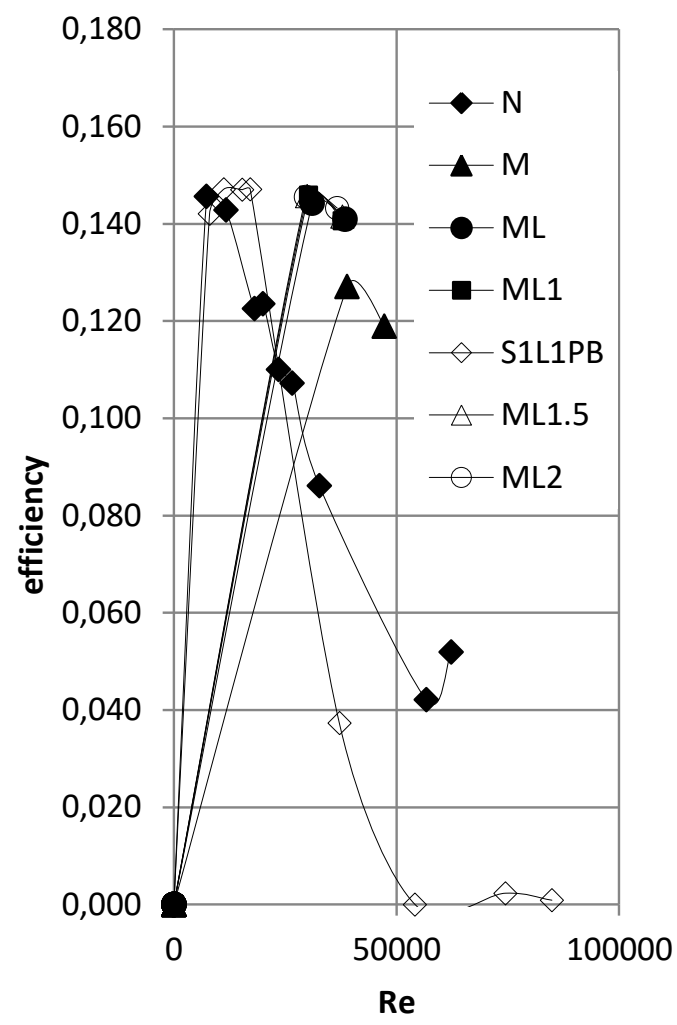

Fig. 17. Efficiency with Re number for all experiments
The power extracted from the wind falls below the Betz limit for VAWT of $14.81 \%$ (Fig. 11 Wind power, Betz limit (VAWT) and some power extracted by EM). In a detailed analysis, it is noticed that the power extracted for EM under load (M, ML, ML1, ML1,5 and ML2) approaches the Betz limit and the EM tested without load ( $\mathrm{N}$ and S1L1PB) have another variation.

Specific output power increases with Re number and for all EMs the maximum value is $7.3 / \mathrm{m}^{2}$. For the Savonius Model with $1 \mathrm{~PB}$ the specific power has 1 $\mathrm{W} / \mathrm{m}^{2}$ (no load).

\section{Conclusions}

The experiments followed the model of the behaviour of a vertical axis wind turbine (VAWT) with a level (1L) and two pairs of blades, as the first step in model experiments for multistage (2-5 levels).

Reference was made to a VAWT Savonius model with 1PB and one level (Fig. 1).

All models were tested in the wind tunnel under the same conditions (N, M, ML, ML1, ML1.5, ML2) from maximum wind speed $(4.5 \mathrm{~m} / \mathrm{s})$ at the speed at which the model did not turn.

The items to be explored were: wind speed and wind turbine rotation. There were calculated the specific rate $\lambda$ (TSR) Re number, the specific power, the power extracted, and the conversion efficiency.

For the range of wind speeds used $(4.5-0 \mathrm{~m} / \mathrm{s})$, the rotation of the experimental models depends on the type of experimental model used and the load on the model. With rising load, the speed decreases (Fig. 7).

TSR $(\lambda)$ and Re numbers follow this dependence mathematically (Fig. 8 and Fig. 9).

The power extracted from the experimental models with load approaches the Betz limit (Fig. 12).

Different behaviours of the experimental models loaded versus those that freely rotate shown by the specific power variation with Renumber (Fig. 13).

Regarding conversion efficiency, it approaches the Betz limit (Fig. 15, Fig. 16, Fig. 17). Experimental models tested without load achieve maximum efficiency at low wind speeds of 1.5-2 m/s. The experimental models loaded have the maximum conversion efficiency at $4 \mathrm{~m} / \mathrm{s}$.

Conversion efficiency for TSR values of less than 1 indicates that the experimental models have suffered from airflow quality, with a below approaching of 1 being desirable at least for non-load models.

\section{References}

[1]. Hau Erich, Wind Turbines, Fundamentals, Technologies, Applications, Economics, s.1.: Springler, 2006. 


\section{THE ANNALS OF "DUNAREA DE JOS” UNIVERSITY OF GALATI \\ FASCICLE IX. METALLURGY AND MATERIALS SCIENCE \\ No. 3 - 2018, ISSN 2668-4748; e-ISSN 2668-4756 \\ Article DOI: https://doi.org/10.35219/mms.2018.3.01}

[2]. Dumitrescu H., Georgescu A., Calcului elicei, Cap. 4 Elicea eoliana, Editura Academiei Romane, 1990.

[3]. Smulders P. T., Rotors for wind power, Eindhoven: University of Technology, Eindhoven, Faculty of Physics, $1^{\text {st }}$ edition October 1991, (revised edition January 2004).

[4]. Cristea Gh., Ardelean I., Elemente fundamentale de fizica, Cluj-Napoca: Editura Dacia, 1980.

[5]. Menet J. L., Bourabaa N., Increase in a savonius rotor efficiency.

[6]. Benesh A., Wind turbine system using a vertical axis Savoniustype rotor, US Patent 4784568, 1988.
[7]. Archer Cristina L., Jacobson Mark Z., Evaluation of global wind power, Journal of Geophysical Research, vol. 11, D12110 2005.

[8]. Hansen Martin O. L., Hansen M. L. O, Aerodynamics of Wind Turbinesm, $2^{\text {nd }}$ ed., Earthscan, 2008. $2^{\text {nd }} e d .$, Padstow: Earthscan, ISBN: 978-1-84407-438-9, 2008.

[9]. Cazacu N., Lucaci C. B., Functional Model of Savonius Type of Vertical Axis Wind Turbine with Periodic Coupling Adjacent Vertical Blades, The Annals of "Dunarea de Jos" University of Galati. Fascicle IX. Metallurgy and Materials Science, vol. 4, ISSN 1453-083X, 2014. 